\title{
Identifying User Requirements of Mobile Government Services in Malaysia Using Focus Group Method
}

\author{
Ahmad Al Thunibat, Nor Azan Mat Zin and Noraidah Sahari \\ School of Information Science, Faculty of Information Science and Technology, \\ Universiti Kebangsaan Malaysia, Selangor, Malaysia
}

\begin{abstract}
Mobile government implementation in Malaysia is still in its very early stages - indeed a comprehensive m-Government has not been shaped yet. In this regard, we need to investigate the potential needs of users of $\mathrm{m}$-Government services. In addition, there is a need to describe the factors that lead to the integration of the services provided with users' everyday practices. In this research, we examined different groups of citizens with varying needs and practices in the available technologies. Focus groups method is used to collect data. Results show that although awareness of mobile government services is reasonably high, only a small number of Malaysians actually use mobile government services. However, citizens acknowledged that mobile government services can be useful, easy to use and convenient. Moreover, both the discussion groups and the questionnaire addressed the problems, limitations, and improvement needed in mGovernment services which include information content, information presentation, system structure, search alternatives, and navigation logic.
\end{abstract}

Keywords: m-Government, e-Government, Focus group, User requirements

\section{Introduction}

M-Government stands for the use of mobile wireless communication technology within the government administration and tool for delivery of services and information to citizens and business(El-Kiki and Lawrence, 2006) . By connecting a wireless part to a wired end part, m-Government creates and guarantees mobility of information and services for the public, businesses, and the government. Furthermore, convenience in accessing information, real time access to information, and personalization of information access are guaranteed to maximize the benefits of using information and in turn create further advanced eGovernment services.

Mobile government implementation is still in its very early stages. Transition from eGovernment to m-Government requires researching the integration process between the two. It also requires investigation of all the pressures that may affect the transition process. Such pressures differ between nations and include the nation's technological and information infrastructure, mobile device penetration, user acceptance, public and social pressures, and security and privacy (Kushchu and Kuscu, 2003).

Copyright (C) 2011 Ahmad Al Thunibat, Nor Azan Mat Zin and Noraidah Sahari. This is an open access article distributed under the Creative Commons Attribution License unported 3.0, which permits unrestricted use, distribution, and reproduction in any medium, provided that original work is properly cited. Contact author: Ahmad Al Thunibat e-mail: ahmadthunibat@yahoo.com 
According to (Carroll, 2006), success of the $\mathrm{m}$-government requires active engagement of both the government and its citizens since providing services by the government is only one side of the m-Government equation. Another, and more challenging aspect, is achieving acceptance and widespread persistent use of m-Government by citizens. The acceptance of $\mathrm{m}$-Government services can be achieved with a proper design and implementation. Services should be delivered in ways with which the public is already familiar and/ or in which users are actively engaged. In addition, the mobile phone is a perfect device for rapid and brief interaction. Hence, content should be short, targeted and relevant to specific users. Another significant parameter that should be taken into account while designing $\mathrm{m}$-Government services is security. Applications that require security must make minimal demands on the user.

\section{Motivations}

The mobile and wireless communications are expected to play a central role in all aspects of people lives especially Malaysians since the penetration of mobile and wireless technology in Malaysia is very high (Thunibat et al., 2010). The technology will substantially expand on the current concept of "anywhere, at anytime" to a new paradigm: "Individual's quality of life improvement by making available an environment for instant provision and access to meaningful multisensory information and content" (van de Kar and Verbraeck, 2008). This vision statement entails that the starting point of the design of future systems and services should consider a person's basic needs and interests. The basic needs and interests involve comfort and welfare of one's personal, family, professional and private life. The technology should be all about improving the quality of life in terms of creating wealth; improving education; improving job skills; enhancing health, security and safety; and stipulating appropriate entertainment at the right time with appropriate content in a secure and reliable way (van de Kar and Verbraeck, 2008).

Carroll (2005) argues that in the case of using the mobile technologies in a variety of practices, there is little evidence on the convergence of practices in which 'one size fits all' services are likely to meet the expanding needs of the citizens. In view of the evolution and diversity of the nature of using mobile technology and the design of $\mathrm{m}$ Government, services to support the current practice are short-sighted and likely to lead to rapid obsolescence (Carroll, 2005). An evolutionary approach, where a small group of high-value services that can be obtained from a group of technologies developed over time, are likely to be more successful.

In Malaysia, we need to investigate the potential needs of users in terms of $\mathrm{m}$ Government services, where "users" here and henceforth describes citizens who access public sector services using the mobile technology. Additionally, we need to describe the driving factors that lead to successful integration of the services provided by the government to satisfy users' everyday practices. In empirical research, we must examine different groups of citizens with varying needs and practices in relation to the available technologies. At present, it appears that there exists a need to build users' portfolios' of electronic and non-electronic resources to meet their needs in real time, especially when they move from one place to another. However, introduction of new technologies leads to emergence of new practices and, consequently, new requirements for more technological support.

\section{Objective of the Study}

The objective of this study is to gain better understanding of citizens' needs and requirements in an m-Government development project. Additionally, this study explores (i) the motivations for $\mathrm{m}$ Government implementation by the 
government and adoption by the public, (ii) attendant limitations, and (iii) means for improving government services and hence, expanding public acceptance and use of these services.

\section{Research Questions}

1. What are the limitations to utilization of $\mathrm{m}$ Government services among Malaysians?

2. What are the problems that citizens face when they use m-Government services?

3. Why do Malaysians need m-Government and what reasons drive its use by the public?

4. What citizen's requirements for
improvement of the current m-
Government services?

This paper is organized as follows. Section one is an introduction while section two presents an overview of the m-Government services. Section three offers a brief discussion of the m-government initiative in Malaysia. Section four discusses challenges to $\mathrm{m}$-Government implementation in Malaysia. Section five introduces a brief discussion of the focus groups method. Section six elaborates on application of the focus group method in this research. A summary of the output of the focus group discussions on mobile government services is presented in section seven. Finally, concluding remarks are presented in section eight.

\section{Mobile Government Services}

The e-Government initiatives have failed to live up to expectations of citizens, however the mobile government initiatives can rebuild trust through faster interaction with the citizens and more effective and efficient service delivery (Song and Cornford, 2006, Gang, 2005). The stable interaction and managed fluid organization with great potential for enhanced hierarchy and vertical integration can provide a suitable underpinning for mobile government initiatives (Gang, 2005). M-Government offers a new level of immediacy, effectiveness, and convenience in the type of service delivery. Mobile communications are fast becoming an accepted part of mainstream society. They provide a dynamic means for citizens, particularly young ones, to interact with local authorities and other government agencies to providing locationbased services. In places with low levels of Internet or PC access, the mobile access is a cost effective way to deliver government information and service. In Japan, where space for home computers can be limited, most citizens under $r$. years of age consider their mobile phone to be their primary Interne-access device (May, 2001).

\section{M-government Initiative in Malaysia}

In 2007, the government of Malaysia launched a new initiative under the electronic government program known as eKL. It is an effort to integrate services delivery across agencies in an effective and efficient manner for the benefit of citizens and businesses within the Klang Valley (Klang Valley is an urban area of Kuala Lumpur and Selangor state) and its vicinity. The eKL initiative focused on the "One government, many agencies" principle to establish a digitally connected Klang Valley whereby services of all government agencies are linked. This joint-up approach enables the sharing of resources and information among government agencies and thereby, facilitates the provision of end-to-end interactive online services 24 hours a day and 365 days a year (24/365) via multiple services channels. One of these channels is the mobile device. The short messaging system (SMS) mobile technology enables citizens on the move to stay connected to government news and services. Within this context, the MySMS initiative was launched. It aimed at standardizing the use of a single number, 15888, for accessing government news and services such as traffic violations summons, payments and renewal of driving licenses. By 2010, there will be 158 additional SMS services for 50 agencies 
including payment services offered by mySMS (Thunibat et al., 2010).

\section{Challenges to the Implementation of $\mathrm{M}$ - Government in Malaysia}

The high level of market penetration of mobile devices in Malaysia will put severe pressure on $\mathrm{m}$-Government implementation. The users will want government services which are compatible with mobile technologies to be deliverable and accessible anywhere and at anytime. This will result in m-Government activities reaching a larger base in a more convenient manner (Kushchu and Kuscu, 2003) .

According to Ahmad et al (2009), until now the m-Government services in Malaysia are very limited and the percentage of utilization of the mobile government services in Malaysia is very low. On the other side, the design of the e-Government official portal doesn't allow citizens to navigate through easily and access the services supposedly offered using their mobile devices. Therefore, there is a need to explore the public's level of acceptance of the mobile government. This is a very important step to identify user requirements and system problems for the purpose of system optimization (Thunibat, 2009).

Malaysia's e-Government initiatives face serious challenges in moving to a higher level of maturity and impact. Major reasons behind this include (Raman et al., 2007, Raman et al.) : (i) lack of public awareness $-60 \%$ of the public are not aware of the services offered; (ii) slow adoption of m-Government applications due to lack of integration and insufficient engagement of key stakeholders (especially users and citizens); (iii) the information provided by government agencies via the e-Government sites is stale and not current; and (iv) the sites are not easy for the novices to navigate. A more challenging aspect, on the other hand, is achieving public acceptance and widespread persistent use of the information and services of the m-Government by citizens.

\section{Methodology}

The m-Government is a new area of research and since there are very few completed studies on this theme, exploratory research is a legitimate method to adopt (Al-khamayseh et al., 2006, Gang, 2005, Bond and Gururajan, 2005).

Due to the fact that m-Government is an emerging discipline, we approached the study goal and objectives through a combination of qualitative and quantitative methods. Where no appropriate theory can be found as a basis for research, we undertake exploratory research (El Kiki and Lawrence, 2006) (Morgan et al., 1998). This involves open-ended studies unguided by theory and intended to provide a new body of empirical knowledge from which theories could be postulated. In order to validate our assumptions, we refer to triangulation with distinct methods for cross-validation on comparable data. This paper presents the first step of this exploratory research by using qualitative method.

Nonetheless, focus groups are an ideal means of exploring research questions related to the practice of communication technology, the purpose of teams and individuals who are experts in communication technology and services, or the users of products or services. People often form an opinion or make a decision through interaction with others (Conklin and Hayhoe, 2010). By "bringing together people of similar backgrounds and experiences to participate in a group interview about major issues that affect them," the focus group provides "high-quality data in a social context where people can consider their own views in the context of the views of others" (Patton, 1980).

\section{The Focus Group Method}

Focus group techniques also called "group discussions" or "user groups" were developed after World War II to assess listeners response to radio programs (Seymour, 2004). The focus group method is 
a qualitative research process designed to elicit opinions, attitudes, beliefs and perceptions from individuals in the effort to gain insights and information about a specific topic (Seymour, 2004). Focus groups can also be used for program development and evaluation, planning, and needs assessment (Krueger and Casey, 2008).

A focus group may be defined as a group of interacting individuals having some common interest or characteristics, brought together by a moderator, who uses the group and its interactions as a way to gain information about a specific or focused issue (Marczak and Sewell, 1998). Unlike the one-way flow of information in a one-on-one interview, focus groups generate data through the "give and take" group discussion. Listening as people share and compare their different points of view provides a wealth of information, not only about what they think about and how they think, but also why they think the way they do.

Focus groups were first used in the world of marketing as a data collection method (Fern, 2001), Now they are being adopted in other domains to identify user needs and feelings that might be missed through other methods of evaluation.

The method becomes an instrument in the public society that allows for hearing the people's voice. A moderator guides the group during discussion of pre-set issues by posing questions that have accordingly been formulated in advance. A focus group is always created with a certain purpose; there is a need objective that the focus group is supposed to respond to. Focus groups are a feasible tool to gather knowledge and enquiries from different users (Morgan, 1998, Axelsson and Melin). Different persons have parts of knowledge about a certain topic and when these parts are brought together and discussed, the total amount of knowledge increases. When establishing a focus group, it is important to state what the group is supposed to construct.
According to Morgan (1998), a focus group often consists of six to eight persons. Nonetheless, other authors proposed different preferable group sizes ranging from four to twelve persons, depending on the purpose of the group discussion. It is a complicated task to choose individuals for the focus group. The participants should be chosen such that they can contribute to the discussion. It can be difficult to encourage persons to join the focus group; they may demand for some benefit in return. It is also important to consider the type of data the focus group discussions will produce and how the data can be analyzed after discussions. Data must be presented in an understandable way and be familiar to the target group (ibid.).

The moderator who leads the focus group must make sure that everyone participates and that no one dominates the group. The discussions atmosphere should be friendly in order to encourage everybody to contribute to the discussion and contribute to fulfilling the purpose of the focus group meeting. The moderator is not supposed to state his or her own opinions before or during the discussion (Krueger and Casey, 2008); instead he/ she should ask questions to the group. Morgan (1998) argues that the focus group can be either structured or unstructured. There are advantages of groups of people who know each other as well as of groups of people who are strangers to one another. Individuals view issues from different perspectives and the focus group is, thus, a suitable method to use in order to understand how different views are constructed and expressed (Graafland-Essers et al., 2003) and provide a deep discussion of the subject of concern.

\section{Employment of the Focus Group Approach in This Study}

In this study, six focus groups were arranged and special attention was paid to homogeneity of the composition of each group such that the particular group is either composited from citizens who used mobile 
government services or those who didn't. Age was the main factor in sample selection for the degree students groups. We decided to compose groups from five university students each. The main reasons for targeting young persons and students were that they represent an important target group of the mobile government portal as young and educated citizens whereby, it's assumed that they will be the first adopters of the new technology and services. The reasons for targeting master degree students particularly in the field of information technology are that they possibly have their own opinions about current mobile services or in the near future. In this study also, two other focus groups of seven members each were arranged. In one group, the participants were administrators in the $\mathrm{m}$-Government project while in the other group, members were administrators in the e-KL initiative (see Table 1).

Each group was led by one moderator. The main assignment was to discuss the present m-Government portal in terms of information, m-services and user interface. The assumed outcome was thoughts about information structure and presentation. Discussions addressed public e-services in general and m-services in particular such as exploration of the motivations for $\mathrm{m}$ Government implementation by the government and adoption by the public, attendant limitations, and means for improving government services and hence, expanding public acceptance and use of these services.

By design, all university student members (one group undergraduate students and the second one master degree students) of two of the four groups had used e-Government services. This was a conscious choice since Morgan (1998) argues that the participants' background should be as much homogenous as possible. The focus groups were directed by the moderator who illustrated the purpose of the focus group meeting, the mobile government field in general, and the m-Government services. He also described the process of using mobile government services in order for every group member to better understand how a web-portal may be used. 
Table 1: Summary of Sample Description

\begin{tabular}{|c|c|c|c|}
\hline Sample & Number of participants & Reason for inclusion & Duration \\
\hline $\begin{array}{l}\text { Degree } \\
\text { students }\end{array}$ & $\begin{array}{l}\text { First group were } \\
\text { students who already } \\
\text { used mobile services ( } 5 \\
\text { students ) } \\
\text { Second group have not } \\
\text { used mobile services yet } \\
\text { ( } 5 \text { students). }\end{array}$ & $\begin{array}{l}\text { They represent an important } \\
\text { target group of the mobile } \\
\text { government services since a } \\
\text { young and educated citizen is } \\
\text { expected to be the first } \\
\text { adopter of the new } \\
\text { technology and services }\end{array}$ & $\begin{array}{l}2 \text { hours for each } \\
\text { group }\end{array}$ \\
\hline $\begin{array}{l}\text { Master degree } \\
\text { information } \\
\text { technology } \\
\text { (IT) students }\end{array}$ & $\begin{array}{l}\text { First group were } \\
\text { students who have not } \\
\text { used mobile services yet } \\
\text { (6 students ) } \\
\text { Second group were } \\
\text { students already used } \\
\text { mobile services (7 } \\
\text { students ). }\end{array}$ & $\begin{array}{l}\text { IT students represent an } \\
\text { important target group of the } \\
\text { mobile government portal } \\
\text { and that they may already } \\
\text { have opinions about current } \\
\text { mobile services or in the near } \\
\text { future as they have a good } \\
\text { knowledge about ICT and } \\
\text { mobile technology so they } \\
\text { can give good suggestions } \\
\text { regarding mobile government } \\
\text { services }\end{array}$ & $\begin{array}{l}90 \text { minutes for } \\
\text { each group }\end{array}$ \\
\hline $\begin{array}{l}\text { m- } \\
\text { Government } \\
\text { initiative } \\
\text { officials }\end{array}$ & $\begin{array}{l}\text { First group: } 7 \text { officials } \\
\text { (including the director } \\
\text { and deputy director of e- } \\
\text { KL initiative in Malaysia } \\
\text { Second group: } 7 \\
\text { participants from } \\
\text { Malaysia Administrative } \\
\text { Modernisation and } \\
\text { Management Planning } \\
\text { Unit (MAMPU). }\end{array}$ & $\begin{array}{l}\text { The participants were } \\
\text { administrators in the e-KL } \\
\text { initiative while the other } \\
\text { group were administrators in } \\
\text { the m-Government project. In } \\
\text { this study there is a need to } \\
\text { understand the administrator } \\
\text { requirements and let them } \\
\text { evaluate (limitations, } \\
\text { problems and importance) } \\
\text { the services that they offer. }\end{array}$ & $\begin{array}{l}2 \text { hours first group } \\
1 \text { hour for the } \\
\text { second group }\end{array}$ \\
\hline
\end{tabular}

After the background and introduction to the topic, a brainstorming activity was performed. In the next phase of the focus group meetings, the participants were asked questions in order to discuss information and m-services on the future portal with respect to search alternatives and service content, among others. Two subgroups were addressed in the discussions; a citizen who already used m-services and a citizen who have not used it yet. Feedbacks from these discussions were then prioritized according to participants' points of view regarding the importance of the proposed m-Government service through a questionnaire designed for this purpose. For the purposes of data collection in this part of the study, group members were asked to respond to a questionnaire made up of a number of items of ranked importance. It should be highlighted, however, that group members were provided with a prototype demonstration of the $\mathrm{m}$-Government services of interest to help them develop ideas sufficient enough for the theme of the study. The next phase of each focus group meetings involved discussions of how mobile government concepts were understood by the participants. The concepts discussed were those which could possibly be misunderstood by the citizens who use, or may use, a portal because of their technical 
literacy. Examples of discussed concepts were quality of mobile service, efficient transactions, strategic data, acceptance, and value for money.

The results showed that most of the concepts and related issues raised and discussed were difficult to understand by the respondents and that the definitions proposed by the participants were more or less incorrect. The meetings concluded with an evaluation of the e-Government portal. The participants were asked to focus on information content, information presentation, search alternatives, and navigation logic. The discussions resulted in many comments with outstanding potential to contribute to improving the performance of the portal. An important suggestion to improve the use of the portal was to add a personalized mservice that may be called "m-Government," where the citizen can login and find all information related to the services which he/ she needs or wants using his/her mobile device, also information content should be updated frequently and presented in more simple and convenient ways. The participants suggested that the new portal should be easy to navigate and compatible with the mobile devices (screen, keyboard and memory limitations), providing different type of search techniques to return more accurate and related information.

In the six focus group meetings, we found that the scenario of letting everybody express his/ her opinion to be the most effective for creating a convenient discussion atmosphere and drawing meaningful feedback. A problem that we encountered was difficulty in engaging participants in the discussions. It was difficult to find incentives for persons and motivate them to participate without offering them some compensation. Our experience indicates that the focus group approach is a feasible method for exploring citizen opinions and attitudes with relation to m-Government services under development. We also recommend that the groups should be homogeneous (Axelsson and Melin, 2007, Graafland-Essers et al., 2003). Instead of having heterogeneous groups, several groups with, for example, different life situations can be arranged in order to illuminate different perspectives and viewpoints. Preparation as well as data analysis after the meetings demand resources, but focus groups as a method require relatively small resources compared to other methods such as surveys performed by telephone or through questionnaires. Instead, this kind of qualitative method unfolds some citizens' attitudes and needs rather than statistically represent data about what citizens as a group really want. This is obviously very important to remember when using data collected from focus groups in e-Government development projects. This fact might be considered as a weakness of the focus groups approach. However, deep "pictures" of some citizens' views are considered a good way to grasp citizen requirements as compared to the total negligence of citizens which is a fact in many e-government projects of today. If focus groups are used to a larger extent than in our project, the groups may also function as a justification to legitimize and launch the mGovernment service.

Focus groups have also turned out to be useful for later stages of m-service development, as in our case. If results from focus group discussions should influence the project's outcome, the method must not be used too late in the development process.

Focus groups can also be used as part of the assessment of the developed m-Government service and, thus, the method can be used in the evaluation phase as well. Our empirical findings through using focus groups can be related to general user participation research, since drawing citizens' opinions and needs in focus groups may be seen as a special case of user involvement in information systems development projects. Mumford (1979) who is a pioneer in the field of user participation distinguishes between three types of user participation that imply varying user influence on the outcome; consultative (i.e. user needs influence the design decisions made by the design team), 
representative (i.e. affected user groups are represented in the design team), and consensus (i.e. all users are involved through communication and consultation) (Mumford, 1979). In line with this, the focus group approach that we have used is closest to consultative user participation.

Although focus groups offer interesting advantages, they have some limitations as well (Mazza and Berre, 2007):

- Responses from group members are not independent of one other. Also, the small number of participants may limit the generalisation of the research findings;

- A dominant member of the group may bias the result, and more reserved members may be hesitant to talk;

- The open-ended nature of the responses make the analysis of the result difficult; and

- A skilled and experienced moderator is needed for an effective research study.

\section{Summary of the Output of the M- Government Services Focus Group Discussions}

As described above, the meetings consisted of three phases; an introduction, prioritization of the importance of discussed information, and a conceptual discussion of the $\mathrm{m}$-Government services. All together, these phases generated a set of information that is essential for future orientation of the development project. Some feedback indicated that the project must build right assumptions regarding citizen requirements while on the other hand; findings extracted from the focus groups will have the effect of motivating the project. Common aspects of these findings were that they represented attitudes of the young generations who lived their entire teenager life as frequent users of the Internet chatting with friends and using the mobile telephone not only for talking but also for navigating the Internet and taking photos, sending short messages (SMS), and listening to music while having in mind certain expectations as to the mobile web portal of the particular government agency. Their high experiences in these kinds of communication media enable them to take some issues for granted. Therefore, they request and prioritize other functions more meaningfully than the inexperienced or less experienced users. Some participants did, for example, mention that they are used to doing everything using their mobiles and that they become irritated when some services are impossible to handle through this device. All participants also had very high expectations of what this kind of portal would have to offer, even though the moderators were asking about the minimum level of services expected. The composition of the group is thus important. Morgan (1998) states that there should be some common characteristics between participants or that the participants have relations and/ or with one another. This could make the discussion climate open-minded and convenient.

Our results show that administrator focus groups are very important for the interest of project developers and development. Feedback from these groups revealed that the current web portal design doesn't support mobile technology. This means that the users cannot navigate the e-Government portal using their mobile devices. Other findings include that the administrators want more security and better user interface in the new portal. They also emphasized the need for increasing the speed of transaction and suggested that the mobile government services set affordable costs so as to motivate citizens to take advantage of these services. Tables (2) summarize the results of this research and relate them to the objectives and research questions. 
Table 2: Results Summary

\begin{tabular}{|c|c|c|}
\hline Objective & $\begin{array}{l}\text { Research } \\
\text { question }\end{array}$ & Results \\
\hline $\begin{array}{l}\text { To explore the } \\
\text { motivations for m- } \\
\text { Government } \\
\text { implementation by } \\
\text { the government and } \\
\text { adoption by the } \\
\text { public (in general). }\end{array}$ & $\begin{array}{l}\text { What reasons } \\
\text { drive its use by } \\
\text { the public? } \\
\text { Why do } \\
\text { Malaysians need } \\
\text { m-Government? }\end{array}$ & $\begin{array}{l}\text { - } \quad \text { Get services anywhere at anytime } \\
\text { - } \quad \text { Increased channels for service } \\
\text { interaction. } \\
\text { - } \quad \text { In situ service delivery for citizens. } \\
\text { - } \quad \text { Better access to data for field users. } \\
\text { - Instant updating of information and } \\
\text { - } \quad \text { Increased productivity of public } \\
\text { - } \quad \text { Bervants. } \\
\text { - } \quad \text { Access speed. } \\
\text { - } \quad \text { Personalization. } \\
\text { - } \quad \text { Curiosity and fun. }\end{array}$ \\
\hline $\begin{array}{l}\text { To Identify the } \\
\text { limitations of using } \\
\text { m-Government by } \\
\text { the public in } \\
\text { Malaysia. }\end{array}$ & $\begin{array}{l}\text { What are the } \\
\text { limitations to } \\
\text { utilization of m- } \\
\text { Government } \\
\text { services in } \\
\text { Malaysians? }\end{array}$ & 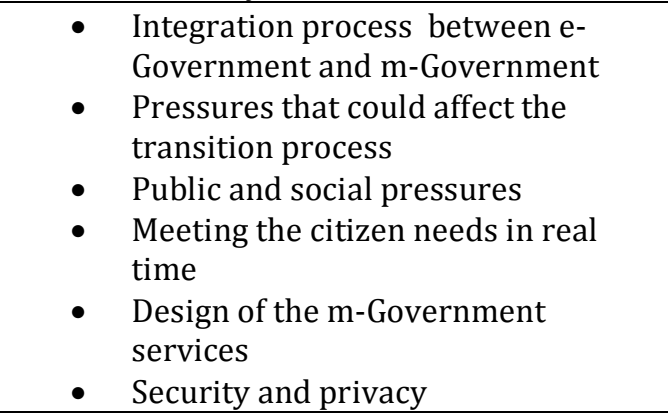 \\
\hline $\begin{array}{l}\text { To investigate the } \\
\text { problem faced by } \\
\text { Malaysian when } \\
\text { they used m- } \\
\text { Government. }\end{array}$ & $\begin{array}{l}\text { What are the } \\
\text { problems that } \\
\text { citizens face } \\
\text { when they use } \\
\text { m-Government } \\
\text { services? }\end{array}$ & $\begin{array}{ll}\text { - } & \text { Difficulty of use } \\
\text { - } & \text { Lack of security } \\
\text { - } & \text { Poor quality of service } \\
\text { - } & \text { Access speed } \\
\text { - } & \text { Service is not personalized enough } \\
\text { - } & \text { High cost of mobile access/ services } \\
\text { - } & \text { Inconvenience in using the mobile } \\
& \text { device }\end{array}$ \\
\hline $\begin{array}{l}\text { To Explores means } \\
\text { for improving } \\
\text { government } \\
\text { services and, hence, } \\
\text { expanding public } \\
\text { acceptance and use } \\
\text { of these services. }\end{array}$ & $\begin{array}{l}\text { What } \\
\text { requirements do } \\
\text { citizens have for } \\
\text { improvement of } \\
\text { the m- } \\
\text { Government } \\
\text { services? }\end{array}$ & $\begin{array}{ll}\text { - } & \text { Improved access speed } \\
\text { - } & \text { Improved security } \\
\text { - } & \text { More e-Government services offered } \\
\text { - } & \text { Improved customer support } \\
\text { - } & \text { Lower cost of mobile access/ } \\
\text { - } & \text { Imprvices } \\
\text { - } & \text { Improved ease of use } \\
& \text { mobile device (e.g. high memory, } \\
\text { - } & \text { Inno of use, user friendly) } \\
\text { (e.g. user profile, portfolio) }\end{array}$ \\
\hline
\end{tabular}


The meetings concluded with an evaluation of the m-Government implementation by exposing the participants to a number of related questions extracted from the discussions. The participants were asked to rank the answers listed according to their importance. The questions and frequency analysis of the feedbacks are presented in the following section.

1-In your opinion, what are the limitations to use of the m-Government services by Malaysians?

- $77 \%$ Integration process between eGovernment and m-Government

- $87 \%$ Pressures that could affect the transition process

- $35 \%$ Public and social pressures

- $90 \%$ Meeting the citizen needs in real time

- $94 \%$ Design of the m-Government services

- $97 \%$ Security and privacy

2-In your opinion, you use the mGovernment services to/ for/ because of

- $98 \%$ Get services anywhere at anytime

- $75 \%$ Saving costs and time

- $80 \%$ Increased channels for service interaction

- $76 \%$ In situ service delivery for citizens

- $86 \%$ Better access to data for field users

- $68 \%$ Instant updating of information and data

- $65 \%$ Increased productivity of public servants
- $88 \%$ Being comfortable

- $90 \%$ Access speed

- $50 \%$ Personalization

- $63 \%$ They help me in business

- $76 \%$ Curiosity and fun

3-In your opinion, the problems you faced when using $\mathrm{m}$-Government services were:

- $34 \%$ Difficulty of use

- $86 \%$ Lack of security

- $53 \%$ Poor quality of service

- $22 \%$ Access speed

- $70 \%$ Service is not personalized enough

- $62 \%$ High cost of mobile access/ services

- $27 \%$ Inconvenience in using the mobile device

4-In your opinion, you will use mGovernment services if there is/are

- $94 \%$ Improved access speed

- $98 \%$ Improved security

- $96 \%$ More e-Government services offered on the mobile devices

- $89 \%$ Improved customer support

- $90 \%$ Lower cost of mobile access/ services

- $92 \%$ Improved ease of use

- $14 \%$ Improved comfort and quality of the mobile device (e.g. high memory, ease of use, user friendly) 
- $73 \%$ Innovative personalized applications (e.g. user profile, portfolio)

Our results show that there are limitations to the m-Government services that are related to security, design, and the extent to which citizen's needs can be met. On the other hand, the most important reasons behind utilizing the m-government services are getting services at any time and any place, new channels for service delivery, more comfortable access, and high access speed. It should be highlighted, however, that these outcomes are consistent with previous studies (Kushchu and Kuscu, 2003, Song and Cornford, 2006, Al-Khamayseh and Lawrence, 2006, Raman et al., Raman et al., 2007).

In sum, the $\mathrm{m}$-Government is still in an early stage. We need more efforts to expand public manipulation of the $\mathrm{m}$-Government services which may be brought about by improving the ease of use, improving the access speed, decreasing the cost, improving the security, enhancing customer support, and expanding the range of services and service providers to cover all government agencies and public needs.

\section{Conclusions}

Our approach of using focus groups to engage users and collect their opinions indicates that focus groups are a valuable tool to use for the benefit of $\mathrm{m}$-Government project design, implementation, and development.

Successful implementation of the focus group research can be achieved by careful planning and by paying attention to important execution details.

Based on the fact that human behavior is rooted both in rational and emotional reactions to stimuli requires that researchers supplement the hard data from quantitative research with "soft data" from qualitative methods. Focus groups, along with one-onone interviews, are of the most effective means of gaining insight into the vast array of emotional aspects of service recipient and user behavior.

The questions presented during the focus group meetings in general should be openended so that as many sound and pertinent feedbacks as possible is obtained. Shortanswer questions, like the "yes" or "no" should be avoided. It is also important to avoid leading questions which suggest the moderator's opinion or the answer that s/he hopes to receive. Questions should also be: (i) clearly formulated and easily understood, (ii) neutral so that their formulation will not influence the answer, (iii) carefully sequenced with easier, general questions preceding the more difficult ones, and (iv) ordered in such a way that the less intimate topics precede the more personal questions.

One additional finding unfolded by this work is that Malaysians welcome the idea of getting services through the mobile device and that they are ready to adopt such new services. However, it seems that they expect more improvement and enhancements to these services to be more effective. Moreover, group discussions showed that respondents faced many problems related to security, cost and quality of services, access speed, interface design and information updating. On the other hand, the young people are more ready to use and utilize the mobile government services in the future than the old ones and they need more convenient services.

Mobile government in Malaysia still needs more research to improve the effectiveness of service deployment and to achieve wide acceptance. As a matter of fact, comprehensive mobile government services in Malaysia are not yet created.

The feedback derived from the administrators focus groups proved critical to $\mathrm{m}$-Government developers, and to project development, successful implementation, and improvement. We were able to identify the administrator requirements and discussed the problems prevailing in the current web 
portal. As a consequence, we found out that the current web portal design doesn't support the mobile technology. This means that the user cannot navigate the eGovernment portal using his/her mobile device. As to administrators demands and to problems encountered by e-Government users, the administrators ask for good user interface, higher transaction speed, and more security in the new portal. They suggested that the mobile government services should offer affordable cost so as to motivate citizens to take advantage of them.

This paper has reported findings of a first test using focus groups to gain better understanding of citizens' needs and requirements in an m-Government development project. We find it necessary for future research to further investigate employment of focus groups as a method and develop techniques to support the performance of focus group meetings in the context of m-Government development projects.

The limitations of this study are that the participants were not representative of all groups of citizen, and thus, the results cannot be generalized since the sample size is not large. Therefore, one important future work is to design a survey to gather user requirements of $\mathrm{m}$-Government services.

\section{References}

Al-Khamayseh, S. \& Lawrence, E. (2006). "Towards Citizen Centric Mobile Government Services: A Roadmap," CollECTeR Europe 2006, 129.

Al-Khamayseh, S., Lawrence, E. \& Zmijewska, A. (2007). "Towards Understanding Success Factors in Interactive Mobile Government," Citeseer.

Al Thunibat, A., Zin, N. A. M. \& Ashaari, N. S. (2010). "Mobile Government Services in Malaysia: Challenges And Opportunities," ITsim2010. Malaysia, IEEE.
Axelsson, K. \& Melin, U. (2007). "Talking to, Not about, Citizens-Experiences of Focus Groups in Public E-Service Development," Electronic Government, 179-190.

Bond, A. \& Gururajan, R. (2005). "Mobile Business: An Exploratory Study To Define A Framework For The Transformation Process," Collaborative Decision Making in the Internet Era, 1-11.

Carroll, J. (2005). "Risky Business: Will Citizens Accept M-government in the Long Term?," Citeseer.

Carroll, J. (2006). "What's in It for Me?': Taking M-Government to the People," BLED 2006 Proceedings, 49.

Conklin, J. \& Hayhoe, G. (2010). "Focus Group Workshop," Professional Communication Conference (IPCC), 2010 IEEE International IEEE.

El Kiki, T. \& Lawrence, E. (2006). "Government as a Mobile Enterprise: RealTime, Ubiquitous Government,"

El-Kiki, T. \& Lawrence, E. (2007). "Mobile User Satisfaction and Usage Analysis Model of mGovernment Services,"

Fern, E. F. (2001). Advanced Focus Group Research, Sage Publications, Inc.

Gang, S. (2005). "Transcending eGovernment: a Case of Mobile Government in Beijing," Citeseer.

Graafland-Essers, I., Ettedgui, E. \& Europe, R. (2003). "Benchmarking e-Government in Europe and the US," Rand Corp.

Krueger, R. A. \& Casey, M. A. (2009). 'Focus Groups: A Practical Guide for Applied Research,' Pine Forge Pr.

Kushchu, I. \& Kuscu, M. H. (2003). “From Egovernment to M-government: Facing the Inevitable," Citeseer. 
Marczak, M. \& Sewell, M. (1998). "Using Focus Groups for Evaluation," Cybernet Evaluation.

May, P. (2001). "Mobile Commerce: Opportunities, Applications, and Technologies of Wireless Business," Cambridge Univ Pr.

Mazza, R. \& Berre, A. (2007). "Focus Group Methodology for Evaluating Information Visualization Techniques And Tools,"

Morgan, D. L. (1998). The Focus Group Guidebook, Sage Publications, Inc.

Morgan, D. L., Krueger, R. A. \& King, J. A. (1998). 'Focus Group Kit,' Sage.

Mumford, E. (1979). 'Consensus Systems Design: An Evaluation of This Approach. Design and Implementation of Computer Based Information Systems,' Sijthoff and Noordhoff, Groningen, Holland.

Patton, M. Q. (1980). "Qualitative Evaluation Methods," Sage Publications Beverly Hills, CA.

Raman, M., Kaliannan, M. \& Yu, C. M. (2007). "E-business and E-government: Issues and Challenges in Malaysia," Information
Technology Journal J, 6, 428-434.

Seymour, A. (2004). 'Focus Groups An Important Tool for Strategic Planning,'

Song, G. \& Cornford, T. (2006). "Mobile Government: Towards A Service Paradigm,”

Thunibat, A. A., Zin, N. A. M., \& Ashaari, N. S. (2009). "Mobile Government Acceptance and Usage in Malaysia," KushchU, I. (Ed. mLife conference Spain.

Van De Kar, E. \& Verbraeck, A. (2008). "Designing Mobile Service Systems," Delft Univ Pr.

\section{Websites}

http://www.myeg.com.my/ [official website of e government services provider in Malaysia , access 24 Dec 2010]

http://www.mampu.gov.my/ [official website of MAMPU in Malaysia, access 24 Dec 2010]

http://www.mysms.gov.my/ [official website of mysms initiative in Malaysia, access 24 Dec 2010] 